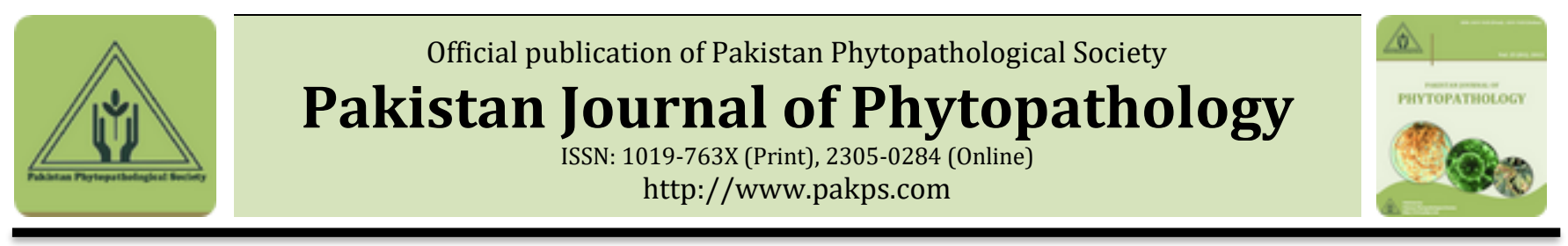

\title{
FIELD CASE INVESTIGATIONS OF MANGO MALFORMATION DISEASE IN FIVE DISTRICTS OF SOUTHERN PUNJAB AND ITS BIOLOGICAL MEDIATED MANAGEMENT UNDER CONTROLLED CONDITIONS
}

\author{
aMuhammad T. Malik*, bSyed A. H. Naqvi, aMalik A. Bakhsh, cTalal Tariq \\ aMango Research Institute, Old ShujaAbad Road, Multan, Pakistan. \\ ${ }^{b}$ Department of Plant Pathology, Faculty of Agri. Sciences and Tech., Bahauddin Zakariya University, Multan, Pakistan. \\ ${ }^{c}$ Comsat Institute of Information Technology, Vehari, Pakistan.
}

\section{A B S T R A C T}

Mango is the king of fruits and keeps the status of national tree in some countries. Pakistani Mangoes are considered to the best in the world due to its shape, taste, flavor and deliciousness. Mango malformation is said to be the hundred century old disease consistently a source of losses for the mango industry. Extensive mango orchard's survey showed a dynamic presence of the disease in the orchards. On the basis of visual systems the trees were evaluated and hence maximum disease severity (41.44) was recorded in District Layyah where the soils were observed more clayey as compared to the other districts of the South Punjab. Similarly, Multan ranked second in the infestation of Mango Malformation disease severity in the orchards while (30.11) was calculated in Lodhran followed by Muzaffar-Garh with (27.11) and Khanewal with (23.33). The fungus was identified as Fusarium mangiferae under the microscope and for the biological mediated management of the pathogen as hypothesized that if successful may be the best possible solution for the management of the disease in the orchards by utilizing the various Trichoderma spp. T. harzianum gave best control against F.mangiferae by depicting 71\% inhibition against the pathogenic fungi. The use of Trichoderma spp against the pathogenic fungi will open new avenues in the biological control tactics of the plant diseases.

Keywords: Mangifera indica, Fusarium mangiferae, Trichoderma spp, Dual culture technique.

\section{INTRODUCTION}

Mango (Mangifera indica) belonging to anacardiaceae family is the national fruit of India, Pakistan, and the Philippines. It is also the national tree of Bangladesh (FAO, 2010). Mango in Pakistan is known as king of fruits due to excellent flavor, luscious taste and high nutritive value (Muhammad et al., 1999). Mangos are nutritionally rich in proteins, carbohydrates, vitamins, fatty acids and amino acids (USDA, 2010). Pakistan produces 1732 thousands tonnes of mango annually being second major fruit crop of country to earn foreign exchange by exporting to Middle East and Europe, hence

\section{Submitted: July 31, 2018}

Revised: August 08, 2018

Accepted for Publication: October 24, 2018

* Corresponding Author:

Email: mtmalik64@hotmail.com

(C) 2017 Pak. J. Phytopathol. All rights reserved. ranked fourth in the world for its production (Govt. of Pakistan, 2014). In Punjab it is grown in districts of Multan, Muzaffar-Garh, Bahawalpur, Rahim Yar Khan, Khanewal, Jhang, Dera Ghazi Khan, Lodhran and Bahawalpur. Many pathosystems of mango crop are responsible for its low yield and inferior quality. A total of eighty three diseases of mango fruit and tree have been reported in the world consisting of fifty two fungal, three bacterial, three by parasitic nematodes and twenty five are listed as miscellaneous diseases and disorders (Pernezny and Simone, 2000). Twenty seven diseases of mango tree and fruit have been reported to be present in Pakistan (Ghafoor and Khan, 1976).

Mango malformation is seriously destructive disease in Pakistan. Typical symptoms are length of primary axis and secondary branches of panicle, which makes flowers, appear in clusters. The flower buds are transformed into vegetative buds, and a large number of 
small leaves and stems, characterized by appreciably reduced internodes, give appearance of a witches' broom. Tree with the disease developed galls in the leaf axils of flush tissue that had been produced at least six months earlier.

There are two distinct stages of mango malformation viz., vegetative and floral (Kumar and Beniwal, 1987). Vegetative malformation (VM), first described in 1953 (Nirvan, 1953), is more pronounced on young seedlings, but also appears on mature trees. Typical symptoms in seedlings are loss of apical dominance and swelling of vegetative buds in the leaf axil or at the tip. The seedlings then produce small shootlets bearing small, scaly leaves (Nirvan, 1953) with a bunch-like appearance, the so-called bunchy-top (BT) stage (Kumar and Beniwal, 1987). Seedlings frequently sprout vegetative buds all over the internodes or produce witches' broom-like symptoms. Those that develop severe VM early, particularly at the apex, remain stunted and die young, whereas those that are infected later resume normal growth above the malformed areas. Malformed seedlings have a shallower root system with few tertiary roots. Vegetative buds on shoots also sprout in trees and produce bunchy growth that eventually dries, but may sprout again the next season.

Development of VM on most branches in a tree leads to considerably reduced or no flowering. Generally, a branch showing VM produces malformed inflorescences (Nirvan, 1953). Symptoms of floral or blossom malformation appears with the emergence of inflorescences. Flowers in a malformed inflorescence (MIIMIS) are much enlarged and crowd the generally hypertrophied axes of the panicle, thus producing no fruit or aborting early (Kumar and Beniwal, 1987). Such panicles appear greener and increased and crowded branching generally causes them to be heavier. A severely malformed inflorescence produces far more flowers, though most remain unopened. Frequently, but not always, the sex-ratio (hermaphrodite vs male) of flowers in a MI decreases. Pistils in malformed hermaphrodite flowers are usually nonfunctional (36) and pollen exhibits poor viability (Kumar and Beniwal, 1987). The extent of infection varies from tree to tree and from branch to branch within a tree (68), and considerable symptom variation occurs in a MI (Kumar and Beniwal, 1987). Both healthy and MI may appear on the same shoot tip.
Furthermore, a largely healthy panicle may have one or more malformed branches or even a few malformed flowers. MIs remain green and continue to bear flowers even after fruit setting in normal panicles (Kumar and Beniwal, 1987). Internal symptoms include: the development of hyperplastic and hypertro-phied cells in malformed vegetative and floral parts (Kumar and Beniwal, 1987); malformed flowers with inflated disks; undifferentiated or poorly differentiated ovules in infected hermaphrodite flowers; degenerating or undeveloped embryos in diseased fruit. Late-stage symptoms of $\mathrm{Zn}$ deficiency in seedlings and trees may be confused with those of malformation, but are clearly distinguishable in early stage symptoms (Kumar and Beniwal, 1987).

Mango malformation is caused by Fusarium mangiferae (Britz et al., 2002). A Fusarium toxin has been found to play a role in the malformation symptoms on mango (Usha et al, 2009). Isolations from malformed parts have ever displayed the dominance of $F$. mangiferae. $F$. mangiferae was found widely distributed in symptomatic tissues of mango obtained from diverse origins showing upto $97.0 \%$ infection (Iqbal et al., 2003). Freeman et al. (2004) confirmed F. mangiferae as etiological agent of MMD by artificial inoculations. Conidia of the pathogen were reduced quickly in soil under controlled laboratory and field conditions. MMD is the major impediment to establishment of economically profitable orchards. It is intriguing the scientists because of its destructive and widespread nature.

Trichoderma sp. has been studied as a bio-control agent against soil-borne pathogenic fungi (Chet and Inbar, 1994). Many researchers have reported that several strain of Trichoderma has a significant reducing effect on plant diseases caused by Fusarium sp. (Dubey et al., 2007; Gupta et al., 2010). The present research aimed to determine the occurrence of mango malformation in some districts of Punjab, isolation and biological mediated management of causative agent under laboratory conditions.

\section{MATERIALS AND METHODS}

Study site: Current research was conducted at Laboratory of Plant Pathology, Plant Protection Section, Mango Research Institute, Multan (30.2639N, 71.5101E) in mango hub of Punjab, Pakistan.

Survey sites: An extensive random survey was conducted during spring season and early summer of 
2017 in the mango groves of five districts viz., Multan, Muzaffar-Garh, Khanewal, Layyah and Lodhran. In each District, four worst hit areas of disease were randomly selected, set as target and thoroughly surveyed to obtain a fresh status of the disease in the mango growing belt of Punjab. On the whole, 60 mango orchards were randomly visited i.e., 15 orchards in each District covering 50 mango plants of various varieties in whole District were examined by $\mathrm{X}$ method for the mango malformation disease severity.

$$
\text { Disease severity index }=\frac{\text { Sum of all the score of individual plants }}{\text { Total No. of Plants observed }} \times 100
$$

Isolation and identification of the pathogen: The studies to ascertain the association of fungi with the malformation affected mango inflorescence were conducted under the controlled conditions with the collection of 15 samples of each symptomatic and asymptomatic inflorescence from the surveyed sites. Immediately after collection of samples, they were kept into icebox to avoid heating during transit and ensure maximum recovery of fungus while the samples of collected mango inflorescence midges were kept into glass vials with caps and brought to Plant Pathology Laboratory, Plant Protection Section, Mango Research Institute, Multan. Five pieces, 3-5 mm long were excised from 45 samples making a total of 225 bits and the midges were crushed in the pestle and mortar for the isolation of fungi with the same number of pieces. Bits of both samples were surface disinfested in $1 \%$ Sodium hypochlorite $(\mathrm{NaOCl})$ solution for two minutes, rinsed twice with sterilized distilled water, dried on sterilized blotting papers and placed in sterilized $9 \mathrm{~cm}$ Pyrex glass Petri dishes containing Potato Dextrose Agar Medium. The plates containing samples pieces were incubated at $25^{\circ} \mathrm{C}$ temperature receiving the illumination of 600 Lux. The plates were examined after 6-7 days of incubation. The tissue bits yielding different fungi were undergone identification based on characteristics specific for the fungus (Nelson et al., 1983).

Biological mediated management of Fusarium mangiferae through Trichoderma spp: Three isolates of bio-agent Tricoderma namely Tricoderma viride, Tricoderma harzianum and Tricoderma virens were kindly obtained from the Mycology Laboratory of Department of Plant Pathology and evaluated for their efficacy against Fusarium mangiferae. Potato dextrose
Disease severity: Mango malformation was rated on the basis of 0 -to-5modified scale where 0 was the highly resistant response with no disease infestation while 1, 2, 3, 4 and 5 were consisted of 1-20, 21-40, 41-60, 61-80infestation of the disease on plants. Similarly 7 was the highly susceptible response of the plant towards disease with $>80 \%$ infection (Masood et al., 2010). Disease severity was calculated by the formula developed by McKinney (1923) which was further simplified with respect to disease symptoms.

agar media poured aseptically in petri plates having $9 \mathrm{~cm}$ diameter with a volume of $20 \mathrm{ml}$ in each plate and place it for solidification. $5 \mathrm{~mm}$ discs of Fusarium mangiferae and $5 \mathrm{~mm}$ discs of Tricoderma isolates was cut from six days old culture plate with the help of sterilized cork borer and place on PDA in opposite direction in a completely randomized design with three replicates while bio agent was placed separately and served as control. The plates were incubated at $28^{\circ} \mathrm{C}$ for $6-7$ days. Readings were taken after every 24 hours up-to 96 hours and measurements of percentage inhibition were determined by the formula.

$\mathrm{L}=[(\mathrm{C}-\mathrm{T}) / \mathrm{C}] \times 100$

Where, $\mathrm{L}=$ Inhibition of radial mycelial growth.

$\mathrm{C}=$ Pathogen Radial growth measurement in control.

$\mathrm{T}=$ Pathogen Radial growth in the presence of Trichoderma spp.

\section{RESULTS}

Survey results showed that mango malformation disease was a problem of each orchard in Southern Punjab. No orchard was found free from this pathosystem irrespective of the cultural practices adopted at specific locality by the farmers. Maximum disease severity (41.44) was recorded in District Layyah where the soils were observed more clayey as compared to the other districts of the South Punjab. Similarly, Multan ranked second in the infestation of Mango Malformation disease severity in the orchards while (30.11) was calculated in Lodhran followed by Muzaffar-Garh with (27.11) and Khanewal with (23.33). There were many observations which were made during the survey to find out the most possible cause of the disease except the pathogenic fungi promoting the hypertrophy and hyperplasia (Figure 1 \& 2). 


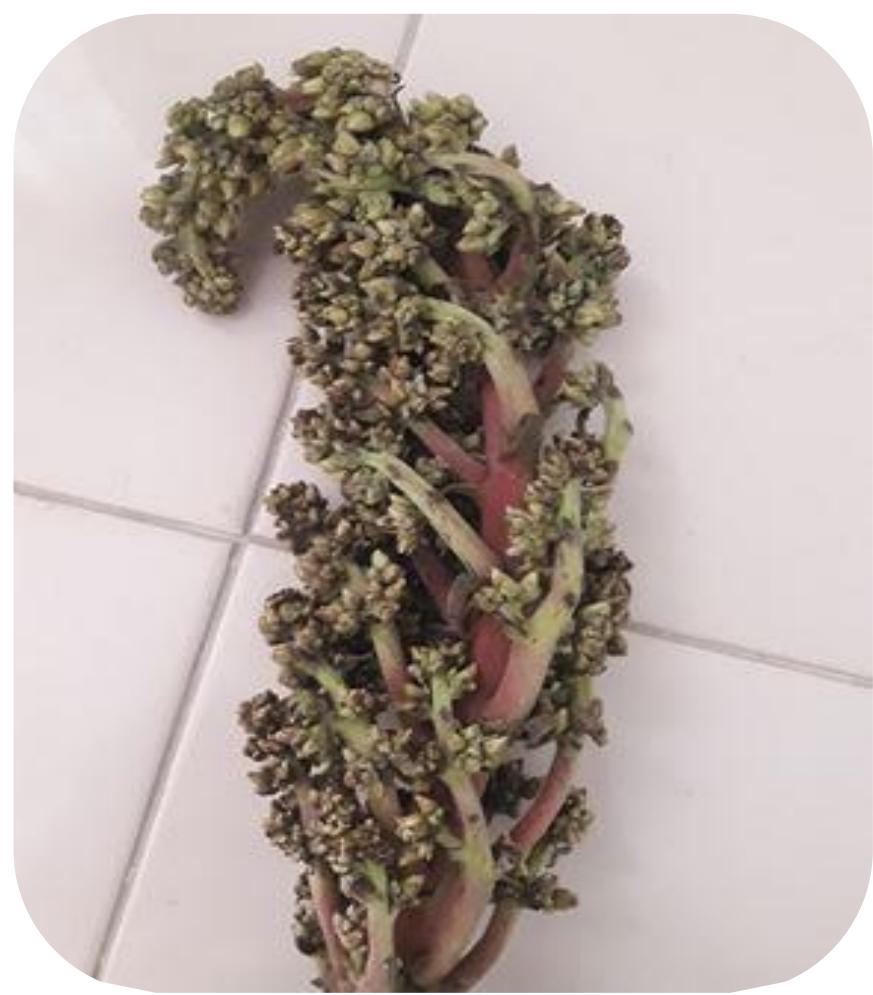

Figure 1. Floral Malformation

Isolation, identification and biological mediated management of Fusarium mangiferae: The fungus was isolated on potato dextrose agar media and multiplied on the very same to perform other experiments. The fungus was identified as Fusarium mangiferae under the microscope and some illustrated editions of the fungal identification manuals.

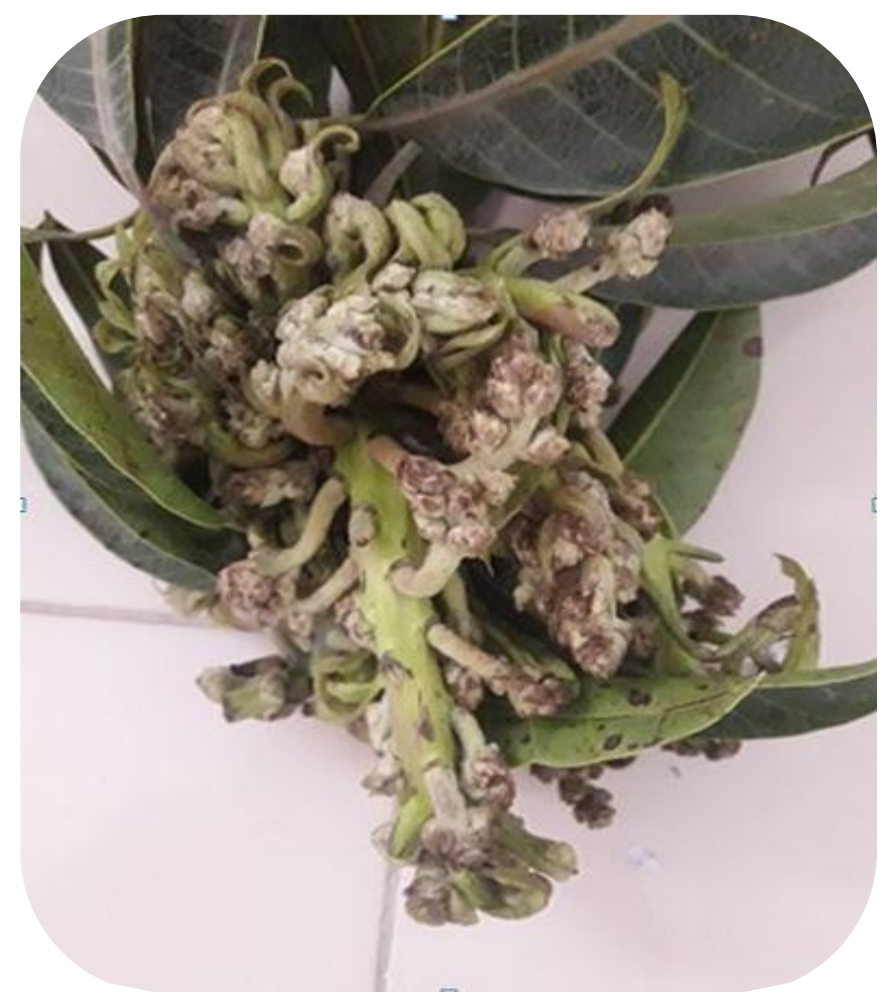

Figure 2. Vegetative Mango malformation

For the biological mediated management of pathogen as hypothesized that if successful may be the best possible solution for the management of disease in orchards by utilizing various Trichoderma spp. $T$. harzianum gave best control against $F$. mangiferae by depicting $71 \%$ inhibition against the pathogenic fungi (Figure 3).

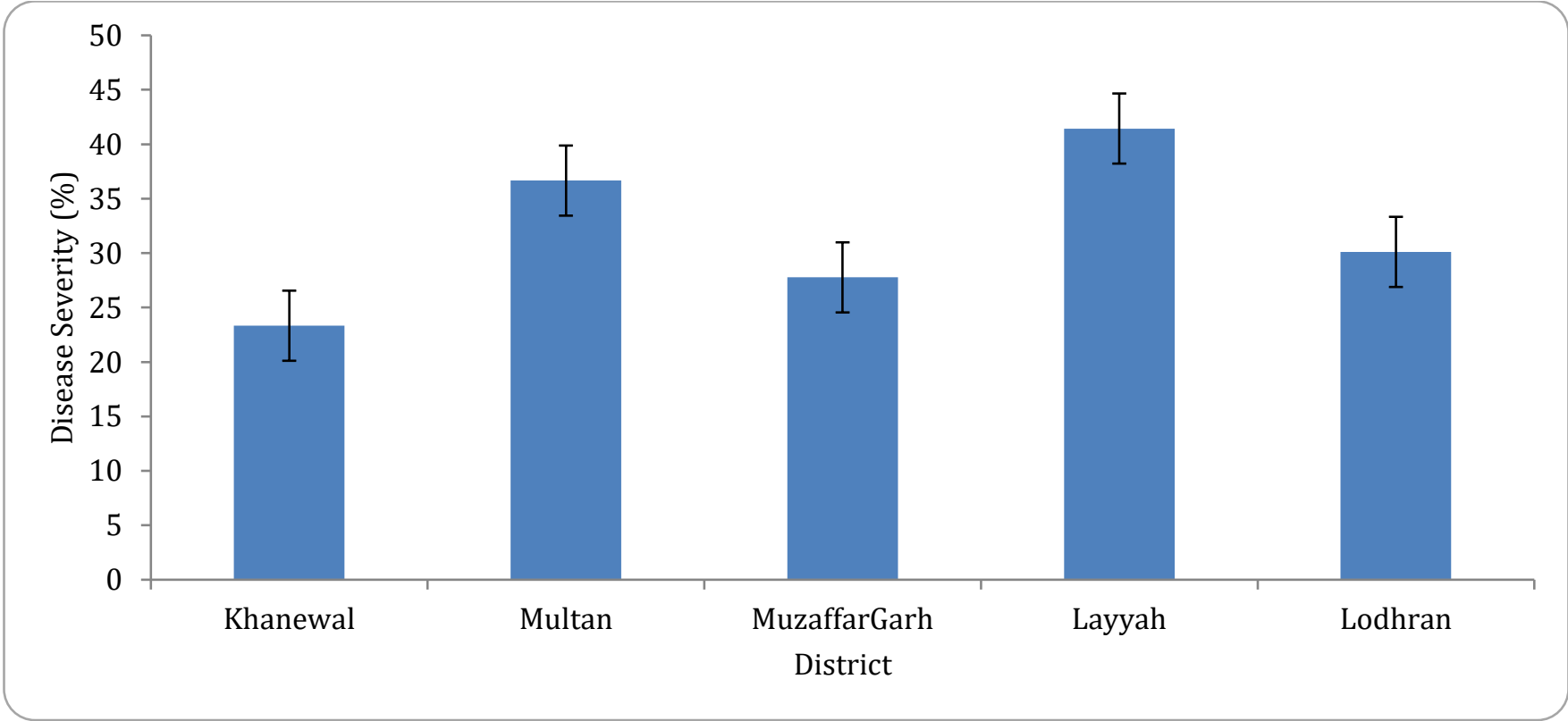

Figure 3. Prevalence of mango malformation disease in surveyed districts of Punjab. 


\section{DISCUSSION}

Mango is the important fruit tree of the world as well as Pakistan. Various problems are the cause of the low production of mango in Pakistan but malformation, a century old disease is among the serious pathosystem hampering mango production because it totally deals with flowers of the disease. Extensive field surveys were conducted in the mango belt of the southern Punjab and it was clear from the survey reports that no orchard was found free from the disease which is a sign of dilemma for the mango growers that in coming years this disease might be the serious note for the mango orchards. Results of the study revealed that no orchard was found free from this pathosystem irrespective of the cultural practices adopted at specific locality by the farmers. Maximum disease severity (41.44) was recorded in District Layyah where the soils were observed more clayey as compared to the other districts of the South Punjab. Similarly, Multan ranked second in the infestation of Mango Malformation disease severity in the orchards while (30.11) was calculated in Lodhran followed by Muzaffar-Garh with (27.11) and Khanewal with (23.33). There were many observations which were made during the survey to find out the most possible cause of the disease except the pathogenic fungi promoting the hypertrophy and hyperplasia. Kumar et al. (1993) tested 100 mono and poly embryonic varieties. Only one variety "Bhaduran" was found disease free. In the present study nine local mono embryonic cultivars were assessed and no one was observed malformation free. Complete resistance has not been observed in anyone variety in Pakistan (Schlosser, 1971). Variation in assessment in different flowering cycles may be observed due to alternate year flowering habit, lack of uniformity in occurrence, temperature fluctuation, diversifying susceptibility from branch to branch and variety to variety. The severity of the disease varies from variety to variety and tree to tree in the same variety. Seasonal variations in the occurrence and severity of problem correlate with ambient temperature at flowering (Majumdar and Sinha, 1972). In Egypt panicles appearing on spring shoots are most severely affected (Shawky et al., 1980). In Florida the heaviest infection occurs under unusually wet conditions (Campbell and Marlatt, 1986). The degree of malformation varies within each cultivar and from cycle to cycle (Azzous et al., 1978. The environmental parameters, host metabolites and mangiferin content cause seasonal variation in disease incidence (Chakrabarti et al., 1997). Most of the Pakistani and Indian cultivars are alternate bearer having uneven fruit set. Symptom expression in malformed panicles may be different and is dependent on type of cultivar, level of hypertrophy and extent of infection. Many studies in the past have found the Trichoderma sp. to be a potential bio-control agent of several soil-borne pathogens (Chet and Inbar, 1994) and hence, Trichoderma was found to be potential in controlling many diseases of crops (Kidwai et al., 2006). The potential of Trichoderma sp. as a bio-control organism for phytopathogenic Fusarium, including competition of Trichoderma sp. and F. moniliforme in vitro has been advocated by Calistru et al. (1997). Bhatnagar and Beniwal (1977) reported that the disease is systemic in nature and indicates that vegetative malformation in nurseries may spread through soil. Hence, application of bio-agents in nursery may be advocated, which may help in the management of vegetative malformation in nurseries along with other control measures. Application of T. harzianum may also control or suppress other soil-borne diseases of mangoes in nurseries. Similarly for the biological mediated management of the disease through Trichoderma spp., it was found very clear that this bio-agent has the mysterious properties for the control of the pathogenic fungi, the same was hypothesized that if successful it will be an achievement for the management of the disease under the field conditions. The fungus was isolated on potato dextrose agar media and multiplied on the very same to perform other experiments. The fungus was identified as Fusarium mangiferae under the microscope and some illustrated editions of the fungal identification manuals. Among the three bio-control agents $T$. harzianum gave best control against $F$. mangiferae by depicting 71\% inhibition against the pathogenic fungi. Although other two also gave good control for the management of the pathogen yet $T$. harzianum was found best for the control of the fungi. A similar kind of result was also reported by Dubey et al. (2007) about Fusarium oxysporum f. sp. ciceris. Kumar and Dubey (2001) reported about the F. solani f. sp. pisi through the production of non-volatile substances. Hajieghrari et al. (2008) also reported 
that Trichoderma harzianum were able to inhibit $F$. graminearum through production of non-volatile substances under controlled condition.

\section{CONCLUSION}

The field case investigations of the disease showed that mango malformation is increasing day by day in the orchards of the area and there is no remedy available for the control of the disease. Biological mediated management showed that all isolates of Trichoderma significantly inhibit the radial growth of $F$. mangiferae and may prove themselves as the best possible solution of the disease if applied in the field in some sort of formulations.

\section{ACKNOWLEDGMENTS}

Authors are highly indebted to the farmers of the respective areas for the affection and care during the survey and their cooperation by providing valuable information's. Specials thanks are also due to Hafiz M. Riaz, Ph.D Scholar Plant Pathology for his courtesy for the provision of the Trichoderma isolates for these experiments.

\section{REFERENCES}

Azzouz, S., Z. Hamdy and I. Dahshan. 1978. Studies on malformed inflorescence of mango, the degree of susceptibility among the different varieties [Egypt]. Albohouth Azziraiya. Agricultural Research and Review, 56:17-27.

Bhatnagar, S. and S. Beniwal. 1977. Involvement of Fusarium oxysporum in causation of mango malformation. Plant Disease Reporter.

Britz, H., E. T. Steenkamp, T. A. Coutinho, B. D. Wingfield, W. F. O. Marasas and M. J. Wingfield. 2002. Two New Species of Fusarium Section Liseola Associated with Mango Malformation. Mycologia, 94: 722.

Chakarbarti, D., R. Kumar and S. Ali. 1997. Mango Malformation: Seasonal Variation in Fusarium moniliforme population in Relation to Environmental Factors, Mangiferin Content and Flushings in Mangifera indica. Indian Journal of Plant Protection, 25: 146-148.

Chet, I. and J. Inbar. 1994. Biological control of fungal pathogens. Applied Biochemistry and Biotechnology, 48: 37-43.

Chet, I. and J. Inbar. 1994. Biological control of fungal pathogens. Applied Biochemistry and Biotechnology, 48: 37-43.

Dubey, S. C., M. Suresh and B. Singh. 2007. Evaluation of
Trichoderma species against Fusarium oxysporum f. sp. ciceris for integrated management of chickpea wilt. Biological Control, 40: 118-127.

FA0. 2010 Food and agriculture organization of the United Nations statistical databases. See http://faostat.fao.org/.

Freeman, S., D. Klein-Gueta, N. Korolev and A. Sztejnberg. 2004. Epidemiology and survival of Fusarium mangiferae, the causal agent of mango malformation disease. Acta Horticulturae: 487491.

Ghafoor, A. G., and S. A. J. Khan. 1976. List of diseases of economic plants in Pakistan. Ministry of Food Agriculture, Karachi, p. 85.

Govt. of Pakistan. 2014. Agriculture Statistics of Pakistan. Ministry of food, agriculture and livestock. Economic, trade and investment wing. Islamabad, Pakistan.

Gupta, M., B. Shaw and A. Mukherjee. 2010. A new glycosidic flavonoid from Jwarhar mahakashay (antipyretic) Ayurvedic preparation. International journal of Ayurveda research, 1: 106.

Hajieghrari, B., M. Torabi-Giglou, M. R. Mohammadi and M. Davari. 2008. Biological potantial of some Iranian Trichoderma isolates in the control of soil borne plant pathogenic fungi. African Journal of Biotechnology, 7(8) 967-972.

Iqbal, Z., A. Saleem and A. Dasti. 2003. Comparative distribution of Fusarium subglutinans in malformed and non-malformed tissues of mango. Pakistan Journal of Phytopathology, 15: 17-20.

Kidwai, MK, Vikas, Srivastava, S and Singh, HB. 2006. Co mpatibility of Trichoderma harzianum to selected fungicide. J Eco-Friend Agric, 1: 156-161.

Kumar, J. and S. Beniwal. 1987. Vegetative and floral malformation: two symptoms of the same disease on mango. FAO Plant Protection Bulletin (FAO).

Kumar, J. and S. P. S. Beniwal. 1987. A method of estimating cultivar susceptibility against mango malformation. Tropical Pest Management, 33: 208-210.

Kumar, J., Beniwal, S. P. S. 1992. Mango malformation. In Plant Diseases of International Importance, ed. J. Kumar, H. S. Chaube, U. S. Singh, A. N. Mukhopadhyay, 3. New York: Prentice Hall. 456 pp.

Kumar, J., U. S. Singh and S. P. S. Beniwal. 1993. Mango Malformation: One Hundred Years of Research. Annual Review of Phytopathology, 31: 217-232. 
Majumder, P. K. and G. C. Sinha. 1972. Seasonal variation in the incidence of malformation in Mangifera indica L. Acta Horticulturae: 223-225.

Masood, A., S. Saeed, N. Iqbal, M. T. Malik and M. R. Kazmi. 2010. Methodology for the evaluation of symptoms severity of mango sudden death syndrome in Pakistan. Pakistan Journal of Botany, 42: 1289-1299.

Muhammad, F., M. Ibrahim and M. A. Pervez. 1999. Effect of Fungicides on Mango Malformation. Pakistan Journal of Biological Sciences, 2: 772-773.

Nelson, P. E., T. A. Toussoun and W. Marasas. 1983. Fusarium species: an illustrated manual for identification.

Nirvan, R. 1953. Bunchy top of young mango seedlings. Science and Culture, 18: 335-336.

Pernezny, K. a. G. W. S. 2000. Diseases of Mango (Mangifera indica L.). www.apsnet.org/ online/common/names/mango.asp
Schlosser, E. 1971. Mango malformation: Symptoms, occurrence and varietal susceptibility. FAO Plant Prot Bull.

Shawky, I., Z. Zidan, A. El-Tomi and D. Dahshan. 1980. Flowering malformation in relation to vegetative growth of Taimour'mangoes. Egyptian Journal of Horticulture, 7: 1-8.

USDA (2010). National nutrient database for standard reference. Release 23. Retrieved 2010-03-21 from the Nutrient Data Laboratory http://www.nal.usda.gov/fnic/foodcomp/search.

Usha, K., B. Singh, P. Praseetha, N. Deepa, D. K. Agarwal, R. Agarwal and A. Nagaraja. 2009. Antifungal activity of Datura stramonium, Calotropis gigantea and Azadirachta indica against Fusarium mangiferae and floral malformation in mango. European Journal of Plant Pathology, 124: 637657. 